
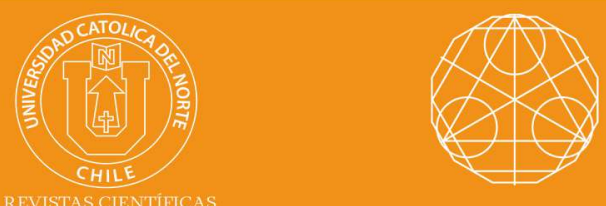

\title{
Equitable total chromatic number of splitting graph
}

\author{
G. Jayaraman* \\ (iD) orcid.org/0000-0003-49095269 \\ D. Muthuramakrishnan ${ }^{* *}$ \\ K. Manikandan ${ }^{* * *}$
}

*Vels Institute of Science, Technology and Advanced Studies, Dept of Mathematics, Chennai, TN, India. $\checkmark$ jayaram07maths@gmail.com

${ }^{* *}$ National College (Autonomous), Trichy, TN, India

$\checkmark$ dmuthuramakrishnan@gmail.com

${ }^{* * *}$ Guru Nanak College (Autonomous), Chennai, TN, India

$\checkmark$ kmanimaths1987@gmail.com

Received: June 2018 | Accepted: March 2019

\begin{abstract}
:
Among the varius coloring of graphs, the concept of equitable total coloring of graph $G$ is the coloring of all its vertices and edges in which the number of elements in any two color classes differ by atmost one. The minimum number of colors required is called its equitable total chromatic number. In this paper, we determine an equitable total chromatic number of splitting graph of $P_{n}, C_{n}$ and $K_{1, n}$.
\end{abstract}

Keywords: Equitable total coloring; Equitable total chromatic number; Splitting graph.

MSC (2010): 05C15.

\section{Cite this article as (IEEE citation style):}

J. Govindasamy, D. Muthuramakrishnan, and K. Manikandan, "Equitable total chromatic number of splitting graph", Proyecciones (Antofagasta, On line), vol. 38, no. 4, pp. 699-705 Oct. 2019, doi: 10.22199/issn.0717-6279-2019-04-0045. [Accessed dd-mm-yyyy].

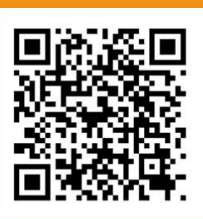

Article copyright: (C) 2019 Govindasamy Jayaraman, D. Muthuramakrishnan and K. Manikandan. This is an open access article distributed under the terms of the Creative Commons Licence, which permits unrestricted use and distribution provided the original author and source are credited.

(cc) BY 


\section{Introduction}

In this paper, we consider only finite undirected graphs without loops or multiple edges. Let $G=(V(G), E(G))$ be a graph with vertex set $V(G)$ and edge set $E(G)$. In 1994, the concept of total coloring $\chi^{\prime \prime}(G)$ was introduced by Behzad [1] and Vizing [11]. A total coloring of a graph $G$ is an assignment of colors to both the vertices and edges of $G$, such that no two adjacent or incident vertices and edges of $G$ are received the same colors. They both conjectured that for any graph $G$ the following inequality holds: $\Delta(G)+1 \leq \chi^{\prime \prime}(G) \leq \Delta(G)+2$, where $\Delta(G)$ is the maximum degree of $G$. It is clear that $\Delta(G)+1$ is the possible lower bound. In 1994, Fu [5] first introduced the concept of equitable total coloring and the equitable total chromatic number of a graph. Gong Kun et.al [3] proved some results on the equitable total chromatic number of $W_{n} \vee K_{n}, F_{m} \vee K_{n}$ and $S_{m} \vee K_{n}$. In 2012, Ma Gang and ma Ming [6] proved some results concerning the equitable total chromatic number of $P_{m} \vee S_{n}, P_{m} \vee F_{n}$ and $P_{m} \vee W_{n}$. Tong et.al [9] proved that the equitable total chromatic number of $C_{m} \square C_{n}$. Girija et.al [2] proved that equitable total chromatic number of Double star graph and fan graph. Gang et.al [7] proved that on the equitable total coloring of multiple join graph. Zhang Zhong-fu [13] proved that on the equitable total coloring of some join graphs. Veninstine vivik et.al [10] proved an algorithmic approach to equitable total chromatic number of wheel graph, Gear graph, Helm graph and sunlet graph.

\section{Preliminaries}

Definition 2.1. The splitting graph[8] of a graph $G$ is obtained from adding to each vertex $v$, a new vertex $v^{\prime}$ such that $v^{\prime}$ is adjacent to every vertex that is adjacent to $v$ in $G$ that is $N(v)=N\left(v^{\prime}\right)$. It is denoted by $S^{\prime}(G)$.

Definition 2.2. For a simple graph $G(V, E)$, let $f$ be a proper $k$ - total coloring of $G$.

$$
|| T_{i}|-| T_{j}|| \leq 1, i, j=1,2, \ldots k .
$$

The partition $\left\{T_{i}\right\}=\left\{V_{i} \cup E_{i}: 1 \leq i \leq k\right\}$ is called a $k$ - equitable total coloring and $\quad \chi_{e t}(G)=\min \{\mathrm{k} / \mathrm{k}$-equitable total coloring of $G\}$ is called the equitable total chromatic number of $G$, where for all $x \in$ $T_{i}=V_{i} \cup E_{i}, f(x)=i, i=1,2, \ldots k$. 
Conjecture 2.3([5]) For any simple graph $G(V, E)$,

$$
\chi_{\text {et }}(G) \leq \Delta(G)+2 .
$$

Conjecture 2.4([14]) For any simple graph $G(V, E)$,

$$
\chi_{e t}(G) \geq \chi^{\prime \prime}(G) \geq \Delta(G)+1 .
$$

Conjecture 2.5([12]) For every graph $G, G$ has an equitable total $k$ - coloring for each $k \geq \max \left\{\chi^{\prime \prime}(G), \Delta(G)+2\right\}$.

Lemma 2.6([4]) For $n \geq 13$, the equitable total chromatic number of Hypo-Mycielski Graph, $\chi_{e t}\left(H M\left(W_{n}\right)\right)=n+2$.

In this paper, we determine an equitable total chromatic number of splitting graph of $P_{n}, C_{n}$ and $K_{1, n}$.

\section{Main Results}

Theorem 3.1. For any positive integer $n \geq 3$, $\chi_{e t}\left(S^{\prime}\left(P_{n}\right)\right)=5$.

Proof. Let $V\left(P_{n}\right)=\left\{v_{i}: 1 \leq i \leq n\right\}$ and $E\left(P_{n}\right)=\left\{e_{i}: 1 \leq i \leq n-1\right\}$, where $\left\{e_{i}: 1 \leq i \leq n-1\right\}$ be the edges $v_{i} v_{i+1}(1 \leq i \leq n-1)$. By the definition of splitting graph, introduce the new vertices $\left\{v_{i}{ }^{\prime}: 1 \leq i \leq n\right\}$ corresponding to the vertices $\left\{v_{i}: 1 \leq i \leq n\right\}$ of $P_{n}$, which are added to obtain splitting graph of path $S^{\prime}\left(P_{n}\right)$. In $S^{\prime}\left(P_{n}\right)$, the vertex set and the edge set is given by $V\left(S^{\prime}\left(P_{n}\right)\right)=\left\{v_{i}: 1 \leq i \leq n\right\} \cup\left\{v_{i}^{\prime}: 1 \leq i \leq n\right\}$ and $E\left(S^{\prime}\left(P_{n}\right)\right)=\left\{e_{i}: 1 \leq i \leq n-1\right\} \cup\left\{e_{i}^{\prime}: 1 \leq i \leq n-1\right\} \cup\left\{e_{i}^{\prime \prime}: 1 \leq\right.$ $i \leq n-1\}$, where $e_{i}(1 \leq i \leq n-1)$ is an edge $v_{i} v_{i+1}(1 \leq i \leq n-1)$, $e_{i}{ }^{\prime}(1 \leq i \leq n-1)$ is an edge $v_{i} v_{i+1}^{\prime}(1 \leq i \leq n-1)$ and $e_{i}^{\prime \prime}(1 \leq i \leq n-1)$ is an edge $v_{i}^{\prime} v_{i+1}(1 \leq i \leq n-1)$. Now we partition the vertex set and edge set of $S^{\prime}\left(P_{n}\right)$ as follows. We consider the following two cases,

Case(i): When $n$ is odd

$$
\begin{aligned}
& T_{1}=\left\{v_{1}, v_{3}, \ldots v_{n}\right\} \cup\left\{e_{2}^{\prime \prime}, e_{4}^{\prime \prime}, \ldots e_{n-1}^{\prime \prime}\right\} \\
& T_{2}=\left\{v_{2}, v_{4}, \ldots v_{n-1}\right\} \cup\left\{e_{1}^{\prime \prime}, e_{3}^{\prime \prime}, \ldots e_{n-2}^{\prime \prime}\right\} \\
& T_{3}=\left\{e_{1}, e_{3}, \ldots e_{n-2}\right\} \cup\left\{v_{i}^{\prime}: 1 \leq i \leq\left\lfloor\frac{n}{2}\right\rfloor\right\} \\
& T_{4}=\left\{e_{2}, e_{4}, \ldots e_{n-1}\right\} \cup\left\{v_{i}^{\prime}:\left\lceil\frac{n}{2}\right\rceil \leq i \leq n-1\right\}
\end{aligned}
$$




$$
T_{5}=\left\{e_{i}^{\prime}: 1 \leq i \leq n-1\right\} \cup\left\{v_{n}^{\prime}\right\}
$$

Clearly $T_{1}, T_{2}, T_{3}, T_{4}$ and $T_{5}$ are independent sets of $S^{\prime}\left(P_{n}\right)$. Its satisfies the inequality ||$T_{i}|-| T_{j}|| \leq 1$ for $i \neq j$. Therefore the graph $S^{\prime}\left(P_{n}\right)$ is equitably total colored with 5 colors. This implies that $\chi_{e t}\left(S^{\prime}\left(P_{n}\right)\right) \leq 5$. Further, since $\Delta=4$, we have $\chi_{e t}\left(S^{\prime}\left(P_{n}\right)\right) \geq \chi^{\prime \prime}\left(\left(S^{\prime}\left(P_{n}\right)\right) \geq \Delta+1 \geq 4+1 \geq 5\right.$. Hence $\chi_{e t}\left(S^{\prime}\left(P_{n}\right)\right)=5$.

Case(ii): When $n$ is even

$$
\begin{aligned}
& T_{1}=\left\{v_{1}, v_{3}, \ldots v_{n-1}\right\} \cup\left\{e_{2}^{\prime \prime}, e_{4}^{\prime \prime}, \ldots e_{n-2}^{\prime \prime}\right\} \\
& T_{2}=\left\{v_{2}, v_{4}, \ldots v_{n}\right\} \cup\left\{e_{1}^{\prime \prime}, e_{3}^{\prime \prime}, \ldots e_{n-1}^{\prime \prime}\right\} \\
& T_{3}=\left\{e_{1}, e_{3}, \ldots e_{n-1}\right\} \cup\left\{v_{i}^{\prime}: 1 \leq i \leq \frac{n}{2}\right\} \\
& T_{4}=\left\{e_{2}, e_{4}, \ldots e_{n-2}\right\} \cup\left\{v_{i}^{\prime}: \frac{n}{2}+1 \leq i \leq n\right\} \\
& T_{5}=\left\{e_{i}^{\prime}: 1 \leq i \leq n-1\right\}
\end{aligned}
$$

Clearly $T_{1}, T_{2}, T_{3}, T_{4}$ and $T_{5}$ are independent sets of $S^{\prime}\left(P_{n}\right)$. Its satisfies the inequality ||$T_{i}|-| T_{j}|| \leq 1$ for $i \neq j$. Therefore the graph $S^{\prime}\left(P_{n}\right)$ is equitably total colored with 5 colors. This implies that $\chi_{e t}\left(S^{\prime}\left(P_{n}\right)\right) \leq 5$. Further, since $\Delta=4$, we have $\chi_{e t}\left(S^{\prime}\left(P_{n}\right)\right) \geq \chi^{\prime \prime}\left(S^{\prime}\left(P_{n}\right)\right) \geq \Delta+1 \geq 4+1 \geq 5$. Hence $\chi_{e t}\left(S^{\prime}\left(P_{n}\right)\right)=5$.

Theorem 3.2. For any positive integer $n \geq 4$, $\chi_{e t}\left(S^{\prime}\left(C_{n}\right)\right)=5$.

Proof. Let $V\left(C_{n}\right)=\left\{v_{i}: 1 \leq i \leq n\right\}$ and $E\left(C_{n}\right)=\left\{e_{i}: 1 \leq i \leq\right.$ $n-1\} \cup\left\{e_{n}\right\}$, where $\left\{e_{i}: 1 \leq i \leq n-1\right\}$ be the edges $v_{i} v_{i+1}(1 \leq i \leq n-1)$ and $e_{n}$ is an edge $v_{n} v_{1}$. By the definition of splitting graph, introduce the new vertices $\left\{v_{i}{ }^{\prime}: 1 \leq i \leq n\right\}$ corresponding to the vertices $\left\{v_{i}: 1 \leq i \leq n\right\}$ of $C_{n}$, which are added to obtain splitting graph of cycle $S^{\prime}\left(C_{n}\right)$. In $S^{\prime}\left(C_{n}\right)$, the vertex set and the edge set is given by

$V\left(S^{\prime}\left(C_{n}\right)\right)=\left\{v_{i}: 1 \leq i \leq n\right\} \cup\left\{v_{i}^{\prime}: 1 \leq i \leq n\right\}$ and $E\left(S^{\prime}\left(C_{n}\right)\right)=\left\{e_{i}: 1 \leq i \leq n-1\right\} \cup\left\{e_{i}^{\prime}: 1 \leq i \leq n-1\right\} \cup\left\{e_{i}^{\prime \prime}: 1 \leq\right.$ $i \leq n-1\} \cup\left\{e_{n}\right\} \cup\left\{e_{n}^{\prime}\right\} \cup\left\{e_{n}^{\prime \prime}\right\}$, where $e_{i}(1 \leq i \leq n-1)$ is an edge $v_{i} v_{i+1}(1 \leq i \leq n-1), e_{n}$ is an edge $v_{n} v_{1}, e_{i}^{\prime}(1 \leq i \leq n-1)$ is an edge $v_{i} v_{i+1}^{\prime}(1 \leq i \leq n-1), e_{n}^{\prime}$ is an edge $v_{n} v_{1}^{\prime}, e_{i}^{\prime \prime}(1 \leq i \leq n-1)$ is an edge $v_{i}^{\prime} v_{i+1}(1 \leq i \leq n-1)$ and $e_{n}^{\prime \prime}$ is an edge $v_{n}^{\prime} v_{1}$. Now we partition the vertex set and edge set of $S^{\prime}\left(C_{n}\right)$ as follows. we consider the following two cases, Case(i): When $n$ is odd

$$
T_{1}=\left\{v_{1}, v_{3}, \ldots v_{n-2}\right\} \cup\left\{e_{1}^{\prime \prime}, e_{3}^{\prime \prime}, \ldots e_{n-2}^{\prime \prime}\right\} \cup\left\{e_{n-1}^{\prime \prime}\right\}
$$




$$
\begin{aligned}
& T_{2}=\left\{v_{2}, v_{4}, \ldots v_{n-1}\right\} \cup\left\{e_{2}^{\prime \prime}, e_{4}^{\prime \prime}, \ldots e_{n-3}^{\prime \prime}\right\} \cup\left\{e_{n}^{\prime}\right\} \cup\left\{e_{n}^{\prime \prime}\right\} \\
& T_{3}=\left\{e_{1}, e_{3}, \ldots e_{n-2}\right\} \cup\left\{v_{i}^{\prime}: 2 \leq i \leq\left\lfloor\frac{n}{2}\right\rfloor+1\right\} \cup\left\{v_{n}\right\} \\
& T_{4}=\left\{e_{2}, e_{4}, \ldots e_{n-1}\right\} \cup\left\{v_{i}^{\prime}:\left\lceil\frac{n}{2}\right\rceil+1 \leq i \leq n\right\} \cup\left\{e_{1}^{\prime}\right\} \\
& T_{5}=\left\{e_{i}^{\prime}: 2 \leq i \leq n-1\right\} \cup\left\{e_{n}\right\} \cup\left\{v_{1}^{\prime}\right\}
\end{aligned}
$$

Clearly $T_{1}, T_{2}, T_{3}, T_{4}$ and $T_{5}$ are independent sets of $S^{\prime}\left(C_{n}\right)$. Its satisfies the inequality ||$T_{i}|-| T_{j}|| \leq 1$ for $i \neq j$. Therefore the graph $S^{\prime}\left(C_{n}\right)$ is equitably total colored with 5 colors. This implies that $\chi_{e t}\left(S^{\prime}\left(C_{n}\right)\right) \leq 5$. Further, since $\Delta=4$, we have $\chi_{e t}\left(S^{\prime}\left(C_{n}\right)\right) \geq \chi^{\prime \prime}\left(\left(S^{\prime}\left(C_{n}\right)\right) \geq \Delta+1 \geq 4+1 \geq 5\right.$. Hence $\chi_{e t}\left(S^{\prime}\left(C_{n}\right)\right)=5$.

Case(ii): When $n$ is even

$$
\begin{aligned}
& T_{1}=\left\{v_{1}, v_{3}, \ldots v_{n-1}\right\} \cup\left\{e_{1}^{\prime \prime}, e_{3}^{\prime \prime}, \ldots e_{n-1}^{\prime \prime}\right\} \\
& T_{2}=\left\{v_{2}, v_{4}, \ldots v_{n}\right\} \cup\left\{e_{2}^{\prime \prime}, e_{4}^{\prime \prime}, \ldots e_{n}^{\prime \prime}\right\} \\
& T_{3}=\left\{e_{1}, e_{3}, \ldots e_{n-1}\right\} \cup\left\{v_{i}^{\prime}: 1 \leq i \leq \frac{n}{2}\right\} \\
& T_{4}=\left\{e_{2}, e_{4}, \ldots e_{n}\right\} \cup\left\{v_{i}^{\prime}: \frac{n}{2}+1 \leq i \leq n\right\} \\
& T_{5}=\left\{e_{i}^{\prime}: 1 \leq i \leq n\right\}
\end{aligned}
$$

Clearly $T_{1}, T_{2}, T_{3}, T_{4}$ and $T_{5}$ are independent sets of $S^{\prime}\left(C_{n}\right)$. Its satisfies the inequality ||$T_{i}|-| T_{j}|| \leq 1$ for $i \neq j$. Therefore the graph $S^{\prime}\left(C_{n}\right)$ is equitably total colored with 5 colors. This implies that $\chi_{e t}\left(S^{\prime}\left(C_{n}\right)\right) \leq 5$. Further, since $\Delta=4$, we have $\chi_{e t}\left(S^{\prime}\left(C_{n}\right)\right) \geq \chi^{\prime \prime}\left(\left(S^{\prime}\left(C_{n}\right)\right) \geq \Delta+1 \geq 4+1 \geq 5\right.$. Hence $\chi_{e t}\left(S^{\prime}\left(C_{n}\right)\right)=5$.

Theorem 3.3. For any positive integer $n, \chi_{e t}\left(S^{\prime}\left(K_{1, n}\right)\right)=2 n+1, n \geq 2$.

Proof. Let $V\left(K_{1, n}\right)=\{v\} \cup\left\{v_{i}: 1 \leq i \leq n\right\}$, where $\left\{v_{i}: 1 \leq i \leq n\right\}$ be the pendent vertices and $\{v\}$ be the root vertex of $K_{1, n}$ and $E\left(K_{1, n}\right)=$ $\left\{e_{i}: 1 \leq i \leq n\right\}$, where $e_{i}$ is an edge $v v_{i}(1 \leq i \leq n)$. Now construct the splitting graph of star, introduce the new vertices $\left\{v^{\prime}\right\}$ and $\left\{v_{i}^{\prime}: 1 \leq i \leq n\right\}$ corresponding to the vertices $\{v\}$ and $\left\{v_{i}: 1 \leq i \leq n\right\}$ of $K_{1, n}$, which are added to obtain splitting graph of star $S^{\prime}\left(K_{1, n}\right)$. In $S^{\prime}\left(K_{1, n}\right)$, the vertex set and the edge sets are given by $V\left(S^{\prime}\left(K_{1, n}\right)\right)=\left\{v_{i}: 1 \leq i \leq n\right\} \cup\left\{v_{i}{ }^{\prime}\right.$ : $1 \leq i \leq n\} \cup\{v\} \cup\left\{v^{\prime}\right\}$ and $E\left(S^{\prime}\left(K_{1, n}\right)\right)=\left\{e_{i}: 1 \leq i \leq n\right\} \cup\left\{e_{i}^{\prime}: 1 \leq\right.$ 
$i \leq n\} \cup\left\{e_{i}^{\prime \prime}: 1 \leq i \leq n\right\}$, where $e_{i}(1 \leq i \leq n)$ is an edge $v v_{i}(1 \leq i \leq n)$, $e_{i}^{\prime}(1 \leq i \leq n)$ is an edge $v v_{i}^{\prime}(1 \leq i \leq n)$ and $e_{i}^{\prime \prime}(1 \leq i \leq n)$ is an edge $v^{\prime} v_{i}(1 \leq i \leq n)$. Now we partition the vertex set and edge set of $S^{\prime}\left(K_{1, n}\right)$ as follows.

$$
\begin{aligned}
& T_{1}=\left\{v, v^{\prime}\right\} \\
& T_{2}=\left\{e_{1}^{\prime}, e_{1}^{\prime \prime}, v_{n}\right\} \\
& T_{3}=\left\{e_{2}^{\prime}, e_{2}^{\prime \prime}, v_{1}^{\prime}\right\} \\
& T_{4}=\left\{e_{3}^{\prime}, e_{3}^{\prime \prime}, v_{2}^{\prime}\right\} \\
& T_{5}=\left\{e_{4}^{\prime}, e_{4}^{\prime \prime}, v_{3}^{\prime}\right\}
\end{aligned}
$$

$$
\begin{aligned}
T_{n-1} & =\left\{e_{n-2}^{\prime}, e_{n-2}^{\prime \prime}, v_{n-3}^{\prime}\right\} \\
T_{n} & =\left\{e_{n-1}^{\prime}, e_{n-1}^{\prime \prime}, v_{n-2}^{\prime}\right\} \\
T_{n+1} & =\left\{e_{n}^{\prime}, e_{n}^{\prime \prime}, v_{n-1}^{\prime}\right\} \\
T_{n+2} & =\left\{e_{1}, v_{n}^{\prime}\right\} \\
T_{n+3} & =\left\{e_{2}, v_{1}\right\} \\
T_{n+4} & =\left\{e_{3}, v_{2}\right\}
\end{aligned}
$$

$$
\begin{aligned}
T_{2 n-1} & =\left\{e_{n-2}, v_{n-3}\right\} \\
T_{2 n} & =\left\{e_{n-1}, v_{n-2}\right\} \\
T_{2 n+1} & =\left\{e_{n}, v_{n-1}\right\}
\end{aligned}
$$

Clearly $T_{1}, T_{2}, T_{3}, T_{4} \ldots T_{2 n+1}$ are independent sets of $S^{\prime}\left(K_{1, n}\right)$. Also $\left|T_{2}\right|=$ $\left|T_{3}\right|=\left|T_{4}\right|=\ldots . .=\left|T_{n+1}\right|=3$ and $\left|T_{1}\right|=\left|T_{n+2}\right|=\left|T_{n+3}\right|=\ldots=$ $\left|T_{2 n}\right|=\left|T_{2 n+1}\right|=2$. Its satisfies the inequality ||$T_{i}|-| T_{j}|| \leq 1$ for $i \neq j$. Therefore the graph $S^{\prime}\left(K_{1, n}\right)$ is equitably total colored with $2 \mathrm{n}+1$ colors. This implies that $\chi_{e t}\left(S^{\prime}\left(K_{1, n}\right)\right) \leq 2 n+1$. Further, since $\Delta=2 n$, we have $\chi_{e t}\left(S^{\prime}\left(K_{1, n}\right)\right) \geq \chi^{\prime \prime}\left(\left(S^{\prime}\left(K_{1, n}\right)\right) \geq \Delta+1 \geq 2 n+1\right.$. Hence $\chi_{e t}\left(S^{\prime}\left(K_{1, n}\right)\right)=$ $2 n+1$. 


\section{References}

[1] M. Behzad, Graphs and their chromatic numbers, Ph. D. thesis, Michigan State University, East Lansing, MI, USA, 1965.

[2] G. Girija, and J. Veninstine Vivik, "Equitable total coloring of some graphs", International Journal of Mathematical Combinatorics, vol. 1, pp. 107-112, Mar. 2015. [On line]. Available: https://bit.ly/338wzRo

[3] G. Kun, Z. Zhongfu and W. Jian Fang, "Equitable total coloring of some join graphs", Journal of mathematical research and exposition, vol. 28, no. 4, pp. 823-828, 2008, doi: 10.3770/j.issn:1000341X.2008.04.010

[4] H. Wang and J. Wei, "The equitable total chromatic number of the graph $\mathrm{HM}\left(\mathrm{W}_{\mathrm{n}}\right)$ ", Journal of applied mathematics and computing, vol. 24, no. 1-2, pp. 313-323, May 2007, doi: $10.1007 / \mathrm{BF} 02832320$.

[5] H. Fu, "Some results on equalized total coloring", Congressus numerantium, vol. 102, pp. 111-119, 1994.

[6] M. Gang and M. Ming, "The equitable total chromatic number of the some join-graphs", Open journal of applied sciences, vol. 2 no. 4B, pp. 96-99, Jan. 2012, doi: 10.4236/ojapps.2012.24B023.

[7] M. Gang, Z. Zhong-fu, "On the equitable total coloring of multiple join graph", Journal of mathematical research and exposition, no. 2, pp. 351-354, 2007. [On line]. Available: https://bit.ly/2q0KcE5

[8] E. Sampathkumar and H. Walikar, "On spliting graph of a graph", Journal of the Karnatak University-Science, vol. 25-26, pp. 13-16, 1980-1981. [On line]. Available: https://bit.ly/2LYpb5a

[9] T. Chunling, L. Xiaohui, Y. Yuansheng and L. Lizhihe, "Equitable total coloring of $\mathrm{Cm}_{2} \mathrm{C}_{\mathrm{n}}$ ", Discrete applied mathematics, vol. 157, no. 4, pp. 596-601, Feb. 2009, doi: 10.1016/j.dam.2008.08.030.

[10] V. Vivik J. y G. Girija, "An algorithmic approach to equitable total chromatic number of graphs", Proyecciones (Antofagasta, En línea), vol. 36, no. 2, pp. 307-324, Jun. 2017, doi: 10.4067/S071609172017000200307

[11] V. Vizing, "On an estimate of the chromatic class of a p- graph", (in Russian), Diskret. Analiz., no. 5, pp. 25-30, 1964.

[12] W. Wang, "Equitable Total Coloring of Graphs with Maximum Degree 3", Graphs and combinatorics, vol. 18, no. 3, pp. 677-685, Oct. 2002, doi: $10.1007 / \mathrm{s} 003730200051$.

[13] Z. Zhang, W. Wang, S. Bau and J. Li, "On the equitable total coloring of some join graphs", Journal of information and computational science, vol. 2, no. 4, pp. 829-834, 2005.

[14] Z. Zhang, J. Zhang, J. Wang, "The total chromatic number of some graph", Scientia Sinica. Series A. 31, 12, pp. 1434-1441, (1988). 